\title{
Acquiring Nominal Gender by Deaf Learners and Hearing Adult Second Language Learners of Dutch
}

Joanne van Emmerik, Jetske Klatter ${ }^{*}$, Roeland van Hout, Ineke van de Craats and Job Schepens

Centre for Language Studies, Radboud University Nijmegen, The Netherlands

*Corresponding author: Jetske Klatter, Centre for Language Studies, Radboud University Nijmegen, PO Box 9103,6500 HD Nijmegen, The Netherlands, Tel: +31 24 361616 ; E-mail: j.klatter@let.ru.nl

Received: April 16, 2014; Accepted: July 29, 2014; Published: July 31, 2014

Copyright: (c) 2014 Emmerik JV, et al. This is an open-access article distributed under the terms of the Creative Commons Attribution License, which permits unrestricted use, distribution, and reproduction in any medium, provided the original author and source are credited.

\begin{abstract}
In this paper the acquisition of Dutch gender by deaf Dutch adults and hearing adult Turkish and Moroccan L2 learners of Dutch is discussed. Although, in the Netherlands, gender acquisition has been studied amply in ethnic minority children and adolescents, research with regard to ethnic minority adults and deaf adults is limited. The analysis of gender data was part of a comprehensive investigation of (writing) skills in these groups. The data were collected via a (semi-) spontaneous language task in which learners were invited to compose The Frog Story on the computer. Discovering and acquiring the gender paradigm turned out to be hard for the learner groups we investigated. Singular common nouns in Dutch take the definite determiner de and neuter nouns the definite determiner het. The results showed that in all learner groups most learners over generalized the use of de to neuter nouns. The reverse, the use of het with common nouns, hardly occurred. With respect to gender acquisition no differences were found between the various learner groups. The outcomes suggest that, in the domain of gender, the acquisition process in deaf learners of Dutch is comparable to the process of acquisition in hearing adult L2 learners of Dutch, despite their different learner situations (late L1 vs. late L2) and, in case of the adult L2 learners, their typologically different first languages. The explanation seems to be passing general learning stages, in combination with the disbalance between the effort required to learn a covert nominal gender distinction and the absence of informative or communicative value in using the gender distinction properly. This disbalance seems to lead to stagnation or fossization in early stages, in all learner groups.
\end{abstract}

Keywords: Language learning; Nominal gender; Written data; Deaf language acquisition; Adult language acquisition

\section{Gender and Acquisition of Gender in Dutch}

The Dutch language distinguishes two nominal gender categories: common and neuter. Gender is morphologically marked via the form of the singular definite article. Common gender nouns take the singular definite article de and neuter gender is linked to the singular definite article het (Table 1). The gender feature is represented as [ \pm common]. The singular indefinite article, which is een for common as well as neuter nouns, and the plural definite article, which is de for both genders, does not have a gender distinction. Nominal gender is also visible on demonstrative pronouns, relative pronouns, and adjectives [1]. Table 2 gives examples for the common nouns appel/ hond ('apple'/'dog') and the neuter noun paard ('horse').

\begin{tabular}{|l|l|l|l|}
\hline Gender of noun & \multicolumn{2}{|l|}{ Definite articles } & Indefinite articles \\
\hline & Singular & Plural & Singular Plural \\
\hline $\begin{array}{l}\text { common } \\
\text { neuter }\end{array}$ & $\begin{array}{l}\text { de } \\
\text { het }\end{array}$ & $\begin{array}{l}\text { de } \\
\text { de }\end{array}$ & $\begin{array}{l}\text { een } \varnothing^{1} \\
\text { een } \varnothing\end{array}$ \\
\hline
\end{tabular}

Table 1: Dutch definite and indefinite articles.

Dutch has a covert gender system according to the classification of Corbett [2], as the grammatical gender of the noun is arbitrary for the majority of nouns. The only transparent cue is the diminutive (see for an overview of other regularities, with their exceptions, Blom et al.,
[3]). All diminutives are neuter nouns. The frequently used diminutive suffix -je (and its variants), such as in het hondje ('the little dog' or 'doggy') in Table 2, makes the noun neuter. The CELEX database shows that the ratio of the distribution of common nouns versus neuter nouns is about 2:1 [4]. Given the fact that $d e$ is also used for all definite plurals, the frequency of de in the input outperforms het.

\begin{tabular}{|l|l|l|l|l|}
\hline $\begin{array}{l}\text { Gender } \\
\text { noun }\end{array}$ & \multicolumn{2}{|l|}{ Definite articles } & \multicolumn{2}{l|}{ Indefinite articles } \\
\hline & Singular & Plural & Singular & Plural \\
\hline $\begin{array}{l}\text { common } \\
\text { neuter }\end{array}$ & $\begin{array}{l}\text { de appel (apple) } \\
\text { de hond (dog) } \\
\text { het hondje (dim., } \\
\text { little dog) } \\
\text { het paard (horse) }\end{array}$ & $\begin{array}{l}\text { de appels } \\
\text { de honden } \\
\text { de hondjes } \\
\text { de paarden }\end{array}$ & $\begin{array}{l}\text { eenappel } \\
\text { eenhond } \\
\text { eenhondje } \\
\text { eenpaard }\end{array}$ & $\begin{array}{l}\varnothing \text { appels } \\
\varnothing \text { honden } \\
\varnothing \text { paarden }\end{array}$ \\
\hline
\end{tabular}

Table 2: Examples of Dutch definite and indefinite articles in a noun phrase. Note: Dutch has two plural suffixes: -s and -en.

In order to cope with nominal gender in Dutch learners first have to acquire the gender feature, to distinguish neuter from common nouns. Moreover they have to learn that there are definite and indefinite articles and that the morphological form of the definite article is dependent on the gender features of the noun. Because of the absence of transparent cues, a learner of Dutch needs to specify and memorize for each noun the value of the gender feature [5]. 
The acquisition of Dutch gender takes a relatively long time for L1 learners, mostly till the age of seven [3,6-8]. In Table 3 the five successive stages of acquisition distinguished in the L1 literature are given. Compared to the stages presented in Keij et al. [9] especially stage 3 has been adapted in this paper.

\begin{tabular}{|l|l|l|}
\hline Stage & Features & $\begin{array}{l}\text { Realization of definite article/noun } \\
\text { combinations }\end{array}$ \\
\hline Stage 0 & Nouns do not carry articles. \\
\hline Stage 1 & {$[+$ definite] } & $\begin{array}{l}\text { There is no gender feature, all nouns carry } \\
\text { de. }\end{array}$ \\
\hline Stage 3 & $\begin{array}{l}\text { [+definite] } \\
\text { variable noun marking }\end{array}$ & $\begin{array}{l}\text { Most nouns are not marked for gender, a } \\
\text { [+definite] [+common] } \\
\text { limited number of neuter nouns carry het, } \\
\text { all other nouns carrying de. }\end{array}$ \\
$\begin{array}{l}\text { variable } \\
\text { marking }\end{array}$ & $\begin{array}{l}\text { All nouns are marked for gender, but } \\
\text { variably and sometimes incorrectly. } \\
\text { Inconsistencies occur and the overuse of } \\
\text { het shows up. }\end{array}$ \\
\hline Stage 4 & $\begin{array}{l}\text { [+definite] [+common] } \\
\text { +definite] [-common] } \\
\text { intrinsic } \\
\text { marking }\end{array}$ & $\begin{array}{l}\text { The target system is attained: common } \\
\text { nouns carry de, neuter nouns het. }\end{array}$ \\
\hline
\end{tabular}

Table 3: Development stages of the nominal grammatical gender feature in Dutch.

L1 children often realize $d e$ as default in the first stage of spontaneous spoken language production [8]. We suppose that they have not acquired the gender feature yet, and that the production of de as default is related to the earlier acquired characteristic of definiteness [1]. Definiteness [+definite] is realised with de in all singular and plural definite contexts. Experimental studies show that L1 children till the age of six massively over generalize the definite article de to neuter nouns, as formulated in stage $2[10,11]$. At a certain moment a learner starts to become conscious that the article het is also part of the language input and that this article is used with certain nouns. This is the very moment that the gender feature is discovered by the learner (stage 3). Blom et al. [3] mentioned that the correct use of the neuter article het increased when the children grew in age, but it was still only $75 \%$ correct at the age of seven. On the other hand, around the age of three, the correct use of $d e$ is at a level of $90 \%$. The relatively late acquisition and unilateral overgeneralization of gender distinguishes Dutch from other languages, like French, German or Spanish, for which gender is already acquired around the age of three [12]. Finally, in stage 4 , intrinsic gender marking results in the target system.

\section{Gender Acquisition by Deaf Learners and Hearing Adult L2 Learners}

Little is known about the acquisition of Dutch gender by deaf people, but omission of articles is frequently mentioned for both children [6] and adults [13]. Van Beijsterveldt [14] investigated the use of noun phrases in written stories by deaf children, youngsters, and adults $(\mathrm{N}=57)$. In all age groups learners did not realize articles, but this tendency decreased with age. A different picture emerged in gender selection, as errors did not diminish with increasing age.
More is known about the acquisition of Dutch gender by learners with another or competing first language. Studies by Blom et al. [15], Cornips and Hulk [16] and Hulk and Cornips [17,18] suggest that both so-called 2L1 children (bilinguals from birth on) and children who started learning the L2 between four and seven massively use de for neuter words, but hardly het with de-words. At first sight this is in line with the findings for L1 learners, but there turns out to be a huge difference. The neuter nouns of the oldest bilingual children (age 10; $5-12 ; 11$ ) in these studies were only in $42.5 \%$ of the cases correctly realized with the article het, while L1 children had already acquired gender at that age. On the basis of these results Cornips and Hulk [16] concluded that there is a qualitative difference between L1 children and bilingual children: the eldest L2 learners have not (yet) reached a mother tongue level and fossilize in the stage of overgeneralization, while L1 children have reached the intended mother tongue level. Hulk and Cornips ascribe the L2 children's fossilization to the qualitatively different input compared to L1 children. The older generations of the ethnic groups to which these L2 children belong, also still over generalize de to neuter words.

On the basis of the results of Hulk and Cornips [17,18], Unsworth [10] looked at the acquisition of Dutch gender by English learners, to whom the drawback of a qualitatively different input does not apply. Accordingly, stagnation in the stage of overgeneralization was not expected. Unsworth tested English-speaking L2 children and adults $(\mathrm{N}=103)$ who performed a (semi-) spontaneous narrative. Most learners indeed over generalized de to neuter nouns. There were also several children and adults who had acquired the correct use of het. Unsworth ruled out the variable age as a crucial factor in the successful acquisition of gender, as some adults performed well. Not so much the age at which input starts, but the quantity of the input was decisive. This conclusion was based on two observations: (i) the correct use of the gender correlated significantly with the length of the language interaction; and (ii) the frequency of the noun played a role in the correct realization of het. If the neuter noun was frequent, the correct use of the article het increased. Lengthy and intensive language input can however not be the only explanation, given the fact that there were still learners who even after a lengthy exposure had not reached the level of a native speaker.

\section{Transfer from $\mathrm{L} 1$ ?}

For all groups concerned in gender acquisition we can safely set aside transfer from the L1. SLN is a language without gender system and without articles, similar to Turkish. The Turkish language only knows the numeral bir ('one') that can be used as an indefinite article [19]. In contrast, the Moroccan Arabic language has definite and indefinite articles, but these are not marked for gender. The Moroccan Arabic language has a dual gender system that distinguishes between male and female gender. Not only do many female words end on $-a$, but the adjective is also marked for gender and agrees with the noun [20]. Blom et al. [15] specify the gender feature in Moroccan Arabic as [ \pm female]. Sabourin [21] shows that the existence of a gender specification in L1 is not sufficient enough to successfully acquire the gender in Dutch as L2. There has to be a semantic or morphosyntactic overlap between the two languages in order to let the learner profit from his L1. Unlike in Dutch, in Moroccan Arabic definiteness is only marked on the article and gender is only marked on the adjective [ \pm female]. So, there is a partial overlap. The marking of gender and definiteness in Moroccan Arabic is much more transparent than in Dutch. 
The language situation in Morocco is complex, most speakers being multilingual [22]. We took Moroccan Arabic as the first language of our adult Moroccan participants, as all of them indicated to be fluent in that language. The multilingual society of Morocco stands in contrast to the fairly monolingual society of Turkey.

\section{Hypotheses}

In this paper we want to compare the acquisition of gender of deaf adults to proficiency-matched non-native hearing adult L2 learners who started acquiring Dutch after puberty.

\begin{tabular}{|l|l|l|l|l|}
\hline & Dutch & Turkish & $\begin{array}{l}\text { Moroccan } \\
\text { Arabic }\end{array}$ & SLN \\
\hline Articles & Yes & No & Yes & No \\
\hline Gender marking & Yes & No & Yes & No \\
\hline $\begin{array}{l}\text { Gender marking } \\
\text { articles }\end{array}$ & Yes & No & No & No \\
\hline Language family & $\begin{array}{l}\text { Indo- } \\
\text { European } \\
\text { (Germanic) }\end{array}$ & $\begin{array}{l}\text { Turkic } \\
\text { (Oghuz) }\end{array}$ & $\begin{array}{l}\text { Afro-Asiatic } \\
\text { (Semitic) }\end{array}$ & $\begin{array}{l}\text { Sign } \\
\text { Language }\end{array}$ \\
\hline Type of acquisition & - & Late DL2 & Late DL2 & $\begin{array}{l}\text { Late DL1 } \\
\text { Early DL2 }\end{array}$ \\
\hline Language input & - & $\begin{array}{l}\text { Auditory, } \\
\text { visual }\end{array}$ & $\begin{array}{l}\text { Auditory, } \\
\text { visual }\end{array}$ & Visual \\
\hline $\begin{array}{l}\text { Levels } \\
\text { proficiency }\end{array}$ & - & Low to high & Low to high & Low to high \\
\hline
\end{tabular}

Table 4: Characteristics of the languages and language learner groups involved in the study. DL1=Dutch as a first language; DL2=Dutch as a second language; SLN=Sign Language of the Netherlands.

Table 4 gives an overview of the characteristics of the languages and the learner groups involved. Some characteristics will be discussed in more detail in the section on method. The information in Table 4 is helpful in understanding the scope of the three hypotheses we have formulated.

With respect to language input in Dutch, the deaf and hearing groups obviously show major differences. First of all, deaf people receive visual input via written Dutch, whereas hearing adult L2 learners may rely on auditory input via spoken language, next to the visual input they get through reading. In most Dutch L2 courses, especially in the initial phase, the focus is on oral instead of written language proficiency. Secondly, there is a difference in age of onset in learning Dutch. Deaf people start around the age of three or four with formal instruction in Dutch via writing (late DL1; or early DL2 when SLN is their first language), whereas adult L2 learners encounter the Dutch language after the age of 15 . The first difference represents a disadvantage for deaf learners: limited input in Dutch because of problematic functioning of the auditory channel. The second difference points to a disadvantage for hearing L2 learners: late input in Dutch because of the age of onset of instruction. The first languages of the participants involved have a wide range. The spoken languages belong to three different language families.

Do all these differences between the learner groups lead to a difference in the end levels that can be obtained? No predictions can be made on the basis of existing data, because we do not know which end level adult deaf people reach in their spoken late L1 and what the variation in proficiency is within this group. Adult L2 learners are marked by wide ranges in the proficiency levels they obtain and they hardly ever succeed in obtaining a native level, but we do not know whether deaf adults show the same range of variation in their performance, perhaps depending on the linguistic structure studied, and whether some of them perhaps succeed in reaching a native level of proficiency.

Why is the acquisition of gender in this comparison of learner groups so interesting? It is to be expected that both deaf learners and hearing late L2 learners of Dutch have a problem with gender. Discovering and acquiring the gender paradigm turns out to be complex for all learners of Dutch, including regular L1 learners, but also for hearing early L2 children and children with Specific Language Impairment [9]. It is not obvious though whether our adult groups of learners show similar problems and a comparable way of dealing with the nominal gender distinction.

The central research question in this study is whether the acquisition of gender by deaf learners shows similarities with the acquisition by hearing adult L2 learners. Despite differences in input and the age at which Dutch is being acquired, the output could be comparable. Another distinction seems to be relevant for the deaf learners. Deaf learners of Dutch start relatively late with the acquisition of Dutch, but the position of Dutch may be different depending on their start with sign language (Sign Language of the Netherlands; SLN). Dutch can be a late L1 or an early L2, SLN being the L1. This distinction is part of the two hypotheses with respect to the acquisition of nominal gender in deaf and hearing learners, where the first one pertains to differences between groups of deaf learners and the second one to differences between the deaf learners in general and the adult or late L2 learner groups:

H1: There is no difference between deaf learners with Dutch as their first or their second language with respect to the acquisition of nominal gender. Both the error frequencies of the groups and the distribution of the adults over the five stages of gender acquisition are similar.

H2: There is no difference between deaf Dutch adults and hearing adult Turkish and Moroccan L2 learners of Dutch with respect to the acquisition of nominal gender. Both the error frequencies of the groups and the distribution of the adults over the five stages of gender acquisition are similar.

In the absence of differences in nominal gender acquisition patterns at intergroup-level, given the two hypotheses above, individual differences can occur between deaf adults and hearing L2 adults in the extent to which they successfully use the gender marker. It seems obvious that individual differences in gender marking are linked to their general command of the Dutch language. We included general language proficiency as a separate factor in order to investigate if general proficiency is directly linked to their success in dealing with the gender distinction. Differences between learners are linked to their proficiency in Dutch. We have expressed this in the following hypothesis:

H3: General proficiency in Dutch is reflected in success in mastering nominal gender marking (gender proficiency).

To test the hypotheses we need to determine how successful learners are in applying the gender distinction in using the definite article. We need to investigate if all research groups show the same 
patterns of overgeneralization, in particular the unilateral overgeneralization of de to het. The number of differences in characteristics between languages and language learner groups in Table 4 indicate that we ventured to be confronted with learner group differences in gender marking. The languages involved (Moroccan Arabic and Turkish) in the adult learner groups are typologically unrelated which may trigger divergent L1 transfer effects. We explained, in addition, that only Moroccan Arabic has a partial, perhaps facilitating overlap with the nominal gender marking of Dutch.

\section{Method}

The analysis of gender data was part of an extensive investigation of written language proficiency in Dutch. Semi-spontaneous written language production was elicited with the use of the well-known picture book Frog, where are you? [23]. The pre-assessment tool of the Instaptoets Anderstalige Volwassenen (IAV) (a standardized C-test; [24]) was used to arrive at an assessment of the general Dutch language proficiency of the participants. Relevant background information was gathered using a written questionnaire.

\section{Participants}

In the present study 46 deaf Dutch adults took part (age 15; 9-60; 3 , $\mathrm{M}=34 ; 6, \mathrm{SD}=12 ; 8$ ), 39 hearing Turkish adult L2 Dutch learners (age 22; 7-47; 7, M=31; 3, SD=6; 7), and 24 hearing Moroccan Arabic adult L2 Dutch learners (age 22; 2-41;0, M=32; 9, $S D=4 ; 6$ ). A group of 10 adult native speakers of Dutch were the control group (age 19; 4-34; 2 , $M=26 ; 3, S D=4 ; 7)$. All participants lived in the Netherlands.

Deaf participants: In the Netherlands, a child is being diagnosed deaf if the average hearing loss of the best ear is 80 decibel or more ${ }^{2}$ [25]. Of the Dutch deaf population, 90 to $95 \%$ is born into hearing families. A minority of deaf children is born into a deaf family.

Most Dutch deaf adults are to some extent bilingual, Dutch and Sign Language of the Netherlands (SLN) being the languages in question. At most schools, systematic input in Dutch through lip reading, writing, and reading was provided from age three or four onwards, which means that the starting point of acquisition of Dutch is roughly the same for the entire group of deaf children.

The deaf group in our study contained 22 male and 24 female adults. The age at the moment of the investigation ranged from 15; 9 to $60 ; 3(\mathrm{M}=34 ; 6, \mathrm{SD}=12 ; 8)$. None of them had in that period a Cochleair Implant $(\mathrm{CI})^{3}$. Cochlear implants are generally associated with better spoken language acquisition [26,27]. One person was born in the Dutch-speaking part of Belgium, but lived in the Netherlands and was dominant in the use of SLN. All participants were born deaf or had become deaf before the age of three. The measured hearing loss was for all participants higher than $90 \mathrm{~dB}$. Of all participants 19 used a hearing aid in daily life.

Within the deaf group, three language learner groups could be distinguished. In labeling these three groups we used the terms late and early in a special way. Late DL1 learners started to acquire their L1 Dutch (= D) when they enrolled at school at the age of three; as adults they had no or limited proficiency in SLN. Late DL1-Early SL2 learners started acquiring their L1 Dutch plus their L2 SLN at the age of three, which is considered late for Dutch, but rather early for their L2 SLN. Early DL2-Early SL1 learners acquire SLN as their first language, and they receive instruction in their second language Dutch at school from age three or four onwards, which is considered early for an L2.

More information on the three groups distinguished is given in Table 5.

\begin{tabular}{|l|l|l|l|l|}
\hline Group & $\begin{array}{l}\text { Hearing status } \\
\text { family members }\end{array}$ & $\mathbf{n}$ & $\begin{array}{l}\text { Age } \\
\text { (range) }\end{array}$ & $\begin{array}{l}\text { Age at start of } \\
\text { acquisition sign } \\
\text { language }\end{array}$ \\
\hline Late DL1 & $\begin{array}{l}\text { hearing parents } \\
\text { (n=19) } \\
\text { deaf siblings (n=2) } \\
\text { deaf family }(n=3)\end{array}$ & 24 & $\begin{array}{l}31 ; 3 \\
(15 ; 9-60 ; 3)\end{array}$ & $\begin{array}{l}\text { No SLN }(n=10) \\
\text { SLN }>4(n=6) \\
\text { SLN }>12(n=5) \\
\text { SLN }>16(n=3)\end{array}$ \\
\hline $\begin{array}{l}\text { Late DL1 - } \\
\text { Early SL2 }\end{array}$ & hearing parents (n=7) & 7 & $\begin{array}{l}38 ; 3 \\
(28 ; 0-49 ; 0)\end{array}$ & $\begin{array}{l}0(n=1)^{4} \\
\text { SLN }>4(n=6)\end{array}$ \\
\hline $\begin{array}{l}\text { Early DL2 - } \\
\text { Early SL1 }\end{array}$ & $\begin{array}{l}\text { deaf parents }(n=3) \\
\text { deaf siblings }(n=2) \\
\text { deaf family }(n=10)\end{array}$ & 15 & $\begin{array}{l}38 ; 2 \\
(17 ; 7-58 ; 4)\end{array}$ & $0(n=15)$ \\
\hline
\end{tabular}

Table 5: The three groups of deaf adults distinguished $(n=46)$.

Turkish and Moroccan Arabic adult L2 learners of Dutch: We selected adult L2 learners from the two largest immigrant groups in the Netherlands. Their country of origin is Morocco and Turkey. The adult L2 learners were selected out of the entire country via many different organizations and teaching establishments where Dutch L2 courses were offered. Important criteria for the selection of participants in this study were that the adults had come to the Netherlands after the age of 16 and had had no earlier contact with the Netherlands. In total 39 Turkish and 24 Moroccan Arabic adults participated in the study ( 32 female and 31 male). The youngest participant was 22; 2 and the eldest 47; 7 with an average age of 31; 9 . Next to Moroccan Arabic, 15 Moroccans had acquired also Berber. All Moroccan participants had some knowledge of the French language. For the Turkish adults the age at the moment of entrance in the Netherlands ranged from $16 ; 0$ to $37 ; 0$ years $(M=23 ; 2, S D=5 ; 1)$, and at the moment of examination from $22 ; 7$ to $47 ; 7$ years $(\mathrm{M}=31 ; 3$, $S D=6 ; 7)$. The length of stay varied between $0 ; 5$ to $28 ; 7$ years $(M=8 ; 1$, $\mathrm{SD}=6 ; 7)$. For the Moroccans the age at the moment of immigration ranged from $18 ; 0$ to $33 ; 0$ years $(M=24 ; 4, S D=4 ; 6)$, and the age at the moment of examination ranged from $22 ; 2$ to $41 ; 0(M=32 ; 9, S D=4 ; 6)$. The length of stay varied between $1 ; 5$ to $20 ; 0$ years $(M=8 ; 4, S D=4 ; 7)$.

Both groups are fairly large and have speakers with a wide range of proficiency in Dutch from low to high, a range that seems to be present in the adult deaf group as well. In addition, the groups have a range of comparable educational levels. A third argument in favour of the two immigrant groups is their language background. Their home languages belong to two different language families (Turkish: Turkic, Moroccan Arabic: Afro-Asiatic) which are in turn different from the language family Dutch belongs to (Indo-European).

\section{Assessment of general language proficiency (C-test)}

The pre-assessment tool of the Instaptoets Anderstalige Volwassenen (IAV; placement test adult L2 learners) (a standardized C-test; [24]) was used to arrive at an assessment of the general Dutch language proficiency of the participants. We have selected this test, because it is one of the few available standardized tests in written format. Participants have 20 minutes to perform the test, but in 
practice they needed no more than 10 minutes. The test consists of 60 items. Each correctly filled in item gives a score of 1 , with a maximum score of 60 . On the basis of the results of the C-test, the participants were divided in three levels: low, semi-advanced and high. Learners with low language proficiency had a score up to a level of 40 , halfadvanced learners had a score between 40 and 51, and learners with high language proficiency had a score of 51 or more. In Table 6 the different test groups are presented on the basis of L1 and language proficiency level in Dutch.

The application of tests measuring general or global proficiency levels has increased over the last years, for instance supported by the Common European Framework of Reference for Languages: Learning, Teaching, and Assessment (CEFR). This standard is nowadays generally accepted as defining global, communicative oriented levels of L2 proficiency in Europe, but is increasingly used in other countries.

\begin{tabular}{|l|l|l|l|l|}
\hline $\begin{array}{l}\text { Level IAV Dutch } \\
\text { Group }\end{array}$ & $\mathbf{n}$ & Low & Semi-advanced & High \\
\hline Deaf: & 46 & $6(25.00 \%)$ & $12(50.00 \%)$ & $6(25.00 \%)$ \\
Late DL1 & 24 & $2(28.57 \%)$ & $1(14.29 \%)$ & $4(57.14 \%)$ \\
Late DL1-Early SL2 & 7 & $0(0.00 \%)$ & $5(33.33 \%)$ & $10(66.67 \%)$ \\
Early DL2-Early SL1 & 15 & & & \\
\hline Turkish & 39 & $27(69.23 \%)$ & $10(25.64 \%)$ & $2(5.13 \%)$ \\
\hline Moroccan & 24 & $9(37.50 \%)$ & $11(45.83 \%)$ & $4(16.67 \%)$ \\
\hline
\end{tabular}

Table 6: Distribution of the deaf Dutch participants and the hearing Turkish and Moroccan participants over the three Dutch proficiency levels of the IAV test.

The distribution of part of the deaf adults is different from the other two groups in that more than half of the deaf Late DL1-Early SL2 and Early DL2-Early SL1 learners is highly proficient in Dutch. In the case of the Turks and Moroccans and in a less marked way the deaf Late $D L 1$ group the highest level is attained least.

\section{Writing task The Frog Story}

Semi-spontaneous written language production was elicited with the use of the well-known picture book Frog, where are you? [23], as an instrument to elicit (semi-) spontaneous, naturalistic, written data. The story consists of 24 pictures without a text.

Our selection of this story is based on the following considerations: (i) the story consists of 24 pictures, which means that we can elicit minimally 24 responses per participant, (ii) using the same booklet leads to stories comparable in content, (iii) the story is frequently used in cross-linguistic research [28] but also by deaf sign language users, normally developing children and in populations with an atypical development [29-31].

All participants had to write The Frog Story in words on a computer. The computer programme ScriptLog ${ }^{5}$ [32] was installed on a laptop for the registration of the writing products. Before the start of the writing task the booklet was made available to the participants. They were allowed to review the whole story first and were told that they should write down the story on the computer. The participants did not need to remember all pictures, because all illustrations appeared on the screen one by one. The screen looked like a normal text editor. The picture out of the booklet was shown every time in the middle on top of the computer screen with the text editor below. When the button 'next' was pushed, the next picture appeared and the previous written text was made invisible. The participants were allowed to return to the previous picture and corresponding text.

\section{Coding procedure}

All written transcripts were coded for gender. The texts were analysed on the occurrence of definite articles and demonstratives in combination with nouns, independent of the question whether the context allowed a definite marker. Other elements that carry gender information, like relative pronouns and attributive adjectives, were not considered in the analyses, as the frequency of relevant occurrences was too low to do a systematic analysis. Every instance or occurrence was coded for:

- determiner, target form: DE (article), DIE (demonstrative, distal), DEZE (demonstrative, proximal) for a common noun or HET (article), DAT (demonstrative, distal), DIT (demonstrative, proximal) for a neuter noun;

- determiner, actual form as written by the participant: DE/DIE/ DEZE (common form) or HET/DAT/DIT (neuter form);

- determiner, class: definite article or demonstrative;

- noun, number: singular or plural;

- noun, category: diminutive or not

The non-target absence of articles or demonstratives was not coded, because we specifically aim at the acquisition of gender and not at the acquisition of definite articles or demonstratives. The frequency of definite variants (articles and demonstratives) varied not only strongly per participant, but also between the groups. The deaf people produced 2958 tokens, with an average of 64.3 per person, the Turkish people produced 1389 tokens, with an average of 35.6, the Moroccans produced 975 tokens, with an average of 40.6 per person, and the control group produced 532 tokens, with an average of 53.2 per person.

\section{Analysis}

Starting point in the analyses was the percentage target realizations in both gender categories on the participant level. The plurals were excluded from further analysis as no errors were found, reducing the data set from 5322 to 4945 occurrences. The group averages are calculated on the basis of the percentages target realizations per participant. The package SPSS was used to carry out the Analyses of Variance (ANOVAs) and the Tukey test that we applied for post hoc comparisons between the participant groups.

First the group results will be discussed. Next we look at the individual patterns in which we present the different answers and look at how the results correlate with the language proficiency level and developmental stages.

\section{Results}

\section{Group results}

In Table 7 an overview is given of the results for all learner groups and the control group.

For all groups it was found that more than $90 \%$ of the words with de were correctly realized, while $50 \%$ or less of the neuter words were correctly realized with het by the learner groups. The lowest score is 
for the Late DL1-Early SL2 group (12.6\%). Apparently, overgeneralization goes in one direction: most learners for example wrote de hond correctly, but in the case of neuter nouns they used primarily de glas instead of het glas. The results also show that the Dutch control group in $10.7 \%$ of the neuter words realized de instead of het. This concerns 11 appearances and is mainly caused by the incorrect specification of one noun: hert ('deer'). Nine times hert was combined with de instead of het. This can be explained by the regional -southern- background of the Dutch informants. The Dictionary of the Dutch Language indicates that in the southern Dutch dialects hert is male.

\begin{tabular}{|l|l|l|l|}
\hline $\begin{array}{l}\text { Percentage correct } \\
\text { Learner groups }\end{array}$ & $\mathbf{n}$ & $\begin{array}{l}\text { Common nouns } \\
\text { (de) }\end{array}$ & $\begin{array}{l}\text { Neuter nouns } \\
\text { (het) }\end{array}$ \\
\hline Deaf: & 46 & $93.9 \%$ & $46.6 \%$ \\
Late DL1 & 24 & $97.1 \%$ & $12.6 \%$ \\
Late DL1-Early SL2 & 7 & $98.6 \%$ & $45.9 \%$ \\
Early DL2-Early SL1 & 15 & & \\
\hline Turkish & 39 & $92.6 \%$ & $35.9 \%$ \\
\hline Moroccan & 24 & $96.6 \%$ & $50.1 \%$ \\
\hline Control group & 10 & $100 \%$ & $89.3 \%$ \\
\hline
\end{tabular}

Table 7: Group results all learners: average percentage correct of gender with common and neuter nouns.

Several learners produced only a few tokens, one learner producing no token at all in the category of neuter nouns. We only included learners in our analyses at the group level that produced minimally five tokens for both neuter and common nouns. As a result, nine learners were excluded: two deaf (one Late DL1, one Late DL1-Early $S L 2)$, six Turkish, and one Moroccan.

The box plots in Figure 1 and Figure 2 present the results for all research groups except the control group. Figure 1 on the common nouns shows that most learners had high correct scores for de words. All three deaf groups have outliers, but not as extremely as the Turkish DL2 group, where three learners have a score of less than $60 \%$ correct.

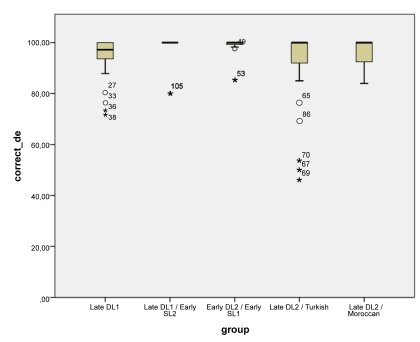

Figure 1: Group results for common nouns, percentage correct realizations?: outliers, values that do not fall in the inner fences; ?: extreme outliers, values more than three times the height of the boxes.

Figure 2 contains the results for the neuter nouns which clearly show lower percentages with a much larger range. The scores for the Late DL1-Early SL2 are the lowest and have the smallest range.

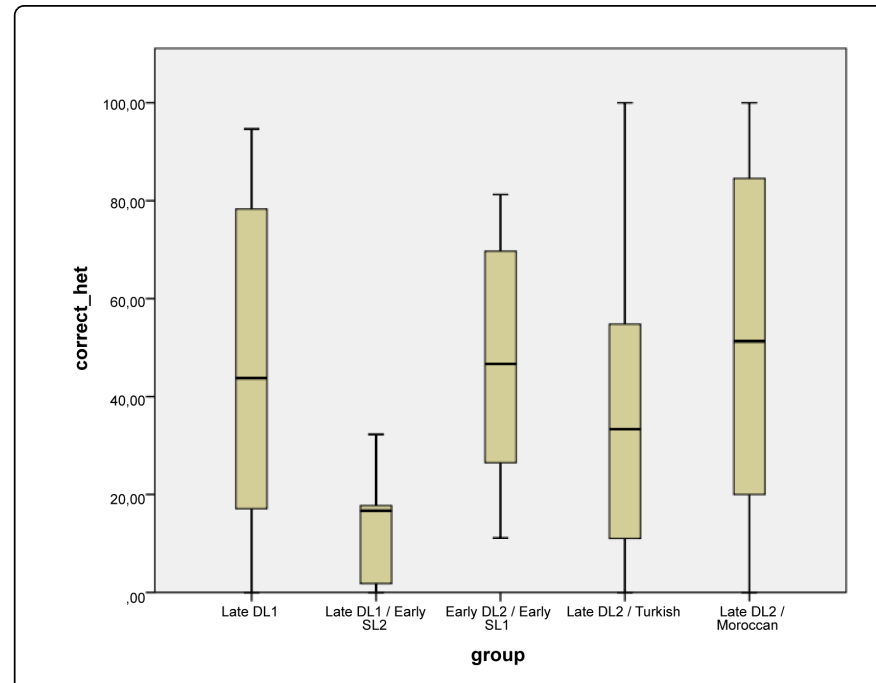

Figure 2: Group results for neuter nouns, percentage correct realizations.

An ANOVA of the correct scores of the common nouns was carried out with learner groups and Dutch proficiency (three levels) as independent variables. Proficiency level was not significant $(\mathrm{F}(2,86)=1.437, \mathrm{p}=.243)$. The learner groups returned a significant result $(\mathrm{F}(4,86)=2.531, \mathrm{p}=.048)$. The interaction between learner groups and proficiency level was not significant $(\mathrm{F}<1)$. A post-hoc analysis (Tukey) of the learner groups did not produce any significant difference, indicating that differences, if they exist, are negligible or small.

The same ANOVA analysis was done for the correct scores on neuter nouns. Proficiency level was significant $(\mathrm{F}(2,86)=7.117, \mathrm{p}=$. $001)$, as well as learner groups $(\mathrm{F}(4,86)=2.588, \mathrm{p}=.042)$. The interaction effect was not significant $(\mathrm{F}(7,86)=1.305, \mathrm{p}=.258)$. No significant group effects were found in the post-hoc analysis of the learner groups. The conclusion is again that group differences are small or negligible.

\section{Individual patterns}

So far the results show the following picture: deaf people as well as the Turkish and Moroccan learners in general do not succeed in correctly realizing het in the case of neuter nouns. On the other hand, the production of de goes well. The question is if the group results indeed are representative for each learner individually, especially in relation to the stages we discerned in Table 3. The individual answer patterns for the selection of gender were analysed with the same type of analysis as was applied in Unsworth [10] and Keij et al. [9]. We applied as boundary values correct scores of $10 \%$ or less or $90 \%$ or more. Stage 0 simply means no determiners. Stage 1 means a correct score of more than $90 \%$ for common nouns and a correct score of less than $10 \%$ for the neuter nouns. Stage 2 still has high correct scores for common nouns (more than 90\%), but higher correct scores for neuter nouns (correct scores higher than 10\%). Stage 4 implies nearly perfect scores (both common and neuter nouns with correct scores larger than $90 \%)$. The remaining patterns belong to stage 3. The classification of the different groups of learners can be found in Table 8. Four of the 109 learners could not be classified because of too few data. 


\begin{tabular}{|l|l|l|l|l|l|}
\hline \multirow{2}{*}{ Stage } & \multicolumn{2}{|l|}{ Deaf } & Turks & $\begin{array}{l}\text { Moroccan } \\
\text { s }\end{array}$ \\
\cline { 2 - 6 } & Late DL1 & $\begin{array}{l}\text { Late DL1 } \\
\text { Early SL2 }\end{array}$ & $\begin{array}{l}\text { Early DL2 } \\
\text { SL1 Early }\end{array}$ & & \\
\hline$n=2$ & 1 & 0 & 0 & 1 & 0 \\
\hline$n=18$ & 5 & 3 & 0 & 8 & 2 \\
\hline$n=65$ & 13 & 3 & 14 & 20 & 15 \\
\hline$n=17$ & 5 & 1 & 1 & 8 & 2 \\
\hline$n=3$ & 0 & 0 & 0 & 0 & 3 \\
\hline
\end{tabular}

Table 8: Individual answer patterns according to the five stages (0-4) in relation to the learner groups.

The results in Table 8 show that the stages with the least and best scores, stages 0 and 4 , apply to only two and three informants respectively, but these extremes seem to support the existence of a relationship between developmental stages and increasing second language proficiency. It is remarkable that the three informants in stage 4 all belong to the Moroccan group. The large majority of the learner groups can be found in stage 2, where correct scores for common nouns are higher than $90 \%$ and for neuter nouns higher than $10 \%$, but less than $90 \%$. It is the most frequent stage in all learner groups. The other respondents are spread over stages 1 and 3 .

In Table 9 the results on the C-test are cross-tabulated with the developmental stages from Table 3 to establish answer patterns.

\begin{tabular}{|c|c|c|c|c|c|c|c|}
\hline \multicolumn{8}{|c|}{ level_C test * stage Cross tabulation } \\
\hline \multicolumn{8}{|l|}{ Count } \\
\hline & & \multicolumn{5}{|c|}{ Stages } & \multirow[t]{2}{*}{ Total } \\
\hline & & ,00 & 1,00 & 2,00 & 3,00 & 4,00 & \\
\hline \multirow{3}{*}{$\begin{array}{l}\text { level_Cte } \\
\text { st }\end{array}$} & 1 & 2 & 11 & 22 & 5 & 0 & 40 \\
\hline & 2 & 0 & 6 & 25 & 7 & 1 & 39 \\
\hline & 3 & 0 & 1 & 18 & 5 & 2 & 26 \\
\hline \multicolumn{2}{|l|}{ Total } & 2 & 18 & 65 & 17 & 3 & 105 \\
\hline
\end{tabular}

Table 9: Dutch language proficiency levels and developmental stages (Table 3).

Table 9 makes clear that for all three language proficiency levels (low, semi-advanced, high) most learners belong to stage 2. Stages 0 and 1 contain more informants with low Dutch language proficiency than semi-advanced and high performers. Stage 4 does include only three informants (Moroccans), but no learner from the low Dutch proficiency level. Stage 3 does not show a distinctive pattern.

Is it possible to deduct a developmental order for the acquisition of gender in combination with the division into Dutch language proficiency levels? The patterns that occur in low language proficiency learners are more indicative of an earlier acquisition stage than the patterns found for the semi-advanced and high language proficiency learners. The two higher $\mathrm{C}$ test levels contain learners of stage 3 and no learners of stage 0 . The overall tendency is that a higher $\mathrm{C}$ test level associates with a higher acquisition stage, but the relationship is far from strong. Learners with a high $\mathrm{C}$ test level may still be in the stage of applying the article de as default. Similar results were found in Hulk and Cornips $[17,18]$ with bilingual children and in Unsworth [10] with English speaking learners of Dutch.

\section{Conclusions and Discussion}

In this study the acquisition of Dutch nominal gender by deaf Dutch adults and hearing Turkish and Moroccan L2 learners of Dutch is investigated. We distinguished three groups of deaf adults, all late L1 or early (child) L2 learners of Dutch, and a hearing second language group of Turks and Moroccans, all late (adult) L2 learners of Dutch. On the basis of previous research we departed from the assumption that the acquisition of Dutch nominal gender is a hard problem for all our learner groups, including even L1 learners of Dutch who turn out to be fairly late (nine to ten years of age) in fully mastering the covert Dutch nominal gender system. The opaqueness of the gender system may have the consequence that all e learner groups, except the early L1 learners, have the same persistent problems in mastering the arbitrary gender distinctions and have to pass similar stages of acquisition. Passing similar stages by later learners of Dutch would imply that nor different early L1s (Moroccan Arabic, Turkish, or SLN) nor different types of input (auditory vs. visual) has a direct impact on learning the Dutch nominal gender paradigm.

Our first and second hypotheses comprised the absence of differences between learner groups in error frequencies or distribution over the stages, first of all with respect to the three deaf groups, and secondly between the deaf groups and the two adult L2 groups. The error frequencies were indeed the same for the different learner groups: there were little errors in the common nouns (less than 10\%) and many errors in the neuter nouns (50-65\%). The use of de instead of het is a characteristic error for all learners. The results match the findings in earlier acquisition studies $[3,10,15,16]$ : the acquisition of het is delayed, and our results show that this applies to deaf learners as well. The analysis at the individual level did again show no differences between the learner groups: no single answer pattern was unique for deaf or for hearing learners.

The hypotheses 1 and 2 imply that there is no L1 influence, although there are differences in the languages involved in dealing with gender. The statistical analysis showed that language background did not have any effect on the correct realization of the definite article. This picture corresponds with the results of Hulk and Cornips [17,18], who did not find a significant difference between Turkish and Moroccan learners either. Nevertheless, Table 9 shows that the Moroccan Arabic learners achieved higher levels of gender proficiency (76\% correct for the most advanced learners, compared to $55 \%$ for the Turkish learners and the deaf learners). The groups of high language proficiency learners were however small, too small, to trace less substantial differences statistically. As said before, the gender specification of Moroccan Arabic may give the Moroccan learners a head start. A Moroccan Arabic learner must notice that the gender feature $[ \pm$ female] from his/her L1 in Dutch is [ \pm common]. Moreover, Moroccan Arabic has a reduced article system. The marking of gender and definiteness in Moroccan Arabic is much more transparent than in Dutch. At the same time, partial language similarities can also be confusing. An additional argument in favor of the Moroccan learners being more proficient is their multilingual background. The sizes of the learner groups are too small however to provide evidence on the benefits of multilingualism. 
What is the role of global language proficiency? The third hypothesis states that general proficiency in Dutch is reflected in success of mastering nominal gender marking (specific gender proficiency). Although this hypothesis was supported by the results on a global level over all groups, it appeared from the individual results that success in the nominal gender distinction was correlated to a limited extent only to global proficiency. How are the learners distributed over the five stages distinguished? The distribution of the individual answer patterns over the different levels of Dutch language proficiency shows that one high proficiency learner stagnated at Stage 1 , producing only de with common as well as neuter nouns. For all three proficiency levels Stage 2 is the most frequent one. The observation that Dutch language proficiency plays a role is also found in other studies. Unsworth [10] shows with a regression analysis that language proficiency is the best predictor for the correct use of het with neuter nouns. In Blom et al. [15] language proficiency in Dutch with Moroccan adult L2 learners appeared however to have no effect on the correct realization of het with neuter nouns. In this study the group adult L2 learners was divided on the basis of the sentence imitation task out of the Taaltoets Alle Kinderen [33] into two language levels (low: I, high: II). It appeared however that also group II had a fairly low Dutch language proficiency score which could explain according to Blom et al. [15] the absence of a significant effect for Dutch language proficiency. This confirms our conclusion that there is a weak correlation only between global proficiency and the acquisition of gender. Individual learners follow different tracks. High proficient learners may stagnate in lower stages of gender acquisition, whereas low proficient learners may arrive at intermediate stages. A lot of variation between learners shows up at all levels of proficiency.

It seems hard for our learners and learner groups to pass beyond Stage 3. A wrong gender choice is not hampering directly the informative value of a spoken message and it normally does not cause a communication breakdown, however non-native the message may sound. Such a communicative circumstance may add to a decrease in learning efforts to master the gender distinction on a native-like level. The disbalance between the efforts required learning a covert nominal gender distinction and the absence of any direct informative or communicative value in using the gender distinction properly seems to be strong enough to prevent non-early successes of acquiring Dutch gender. This particular state of affairs seems to prevent the emergence of structural differences between deaf learners of Dutch (late L1 and early L2) and (late) adult L2 learners of Dutch in acquiring Dutch nominal gender. This conclusion shifts the focus of research towards the importance to study in detail the relationship between acquiring specific linguistic constructions and global indices of language proficiency, particularly when local and global constraints have contrastive values.

\section{Notes}

${ }^{1}$ Dutch also has a plural 0 -form $(\varnothing)$, which is quite difficult to acquire.

${ }^{2}$ See Kolen[34] for a concise historical overview of deafness in the Netherlands.

${ }^{3} \mathrm{~A}$ Cochlear Implant (CI) is a hearing prosthesis which is surgically placed in the cochlea.

${ }^{4}$ This deaf person received input in SLN from early youth.
${ }^{5}$ ScriptLog[32] is a computer programme for registering online writing processes.

\section{References}

1. Van de Craats I (2003) L1 features in the L2 output. In: Hout R van, Hulk A, Kuiken F and Towell R (eds), The lexicon-syntax interface in second language acquisition. Amsterdam/Philadelphia: John Benjamins, pp. 69-96.

2. Corbett G (1991) Gender. Cambridge: University Press.

3. Blom E, Polišenská D, Unsworth S (2008) The acquisition of grammatical gender in Dutch. Los Angeles/London: Sage.

4. Van Berkum J (1996) The psycholinguistics of grammatical gender. PhD Thesis, Max Planck Institute Nijmegen.

5. Carroll S (1989) Second language acquisition and the computational paradigm. Language Learning 39: 535-594.

6. Bol G, Kuiken F (1988) Grammaticale analyse van taalontwikkelingsstoornissen. PhD Thesis, University of Amsterdam.

7. Van der Velde M (2003) Déterminants et pronoms en néerlandais et en français: syntaxe et acquisition. PhD Thesis, University of Paris.

8. Van Kampen J, Wijnen F (2000) Grammaticale ontwikkeling. In: Gillis S and Schaerlaekens A (eds), Kindertaalverwerving. Groningen: Martinus Nijhoff, pp. 225-286.

9. Keij B, Cornips L, Van Hout R, Hulk A, Van Emmerik J (2012) Knowing versus producing. Linguistic Approaches to Bilingualism 2: 379-403.

10. Unsworth $S$ (2008) Age and input in the acquisition of grammatical gender in Dutch. Second Language Research 24: 365-395.

11. Van der Velde M (2004) L'acquisition des déterminants en L1. Acquisition et Interaction en Langue Etrangère 21: 9-46.

12. Franceschina F (2005) Fossilized second language grammars: The acquisition of grammatical gender. Amsterdam/Philadelphia: John Benjamins.

13. Van Herreweghe M, Vermeerbergen M (2003) Flemish sign language and Dutch. In: Granger S, Lerot J and Petch-Tyson S (eds), Corpus-based approaches to contrastive linguistics and translation studies. Amsterdam: Rodopi, pp. 91-103.

14. Van Beijsterveldt L (2009) Written language production in deaf children and adults. PhD Thesis, Radboud University Nijmegen.

15. Blom E, Polišenská D, Weerman F (2008b) Articles, adjectives and age of onset: The acquisition of Dutch grammatical gender. Second Language Research 24: 297-331.

16. Cornips L, Hulk A (2008) Factors of success and failure in the acquisition of grammatical gender in Dutch. Second Language Research 24: 267-295.

17. Hulk A, Cornips L (2006a) The acquisition of definite determiners in child L2 Dutch. In Unsworth S, Parodi T, Sorace A and Young-Scholten M (eds) Paths of development in L1 and L2 acquisition. Amsterdam: John Benjamins, pp. 107-134.

18. Hulk A, Cornips L (2006b) Between 2L1- and child L2 acquisition: An experimental study of bilingual Dutch. In: Lleó C (ed) Cognitive processes in bilinguals. Amsterdam: North Holland, pp. 115-137.

19. Kornfilt J (1997) Turkish. London: Routledge.

20. Harrell R (1962) A short reference grammar of Moroccan Arabic. Washington, D.C.: Georgetown University Press.

21. Sabourin L (2001) L1 effects on the processing of grammatical gender in L2. In: Foster-Cohen S and Nizegorodcew A (eds) EUROSLA Yearbook 2001, pp. 159-169.

22. Fernández M, Miller C, De Ruiter J, Tamer Y (eds) (2013) Evolution des pratiques et représentations langagières dans le Maroc du XXIe siècle. Paris: L'Harmattan.

23. Mayer M (1969) Frog, where are you? New York: Dial Press.

24. Janssen-van Dieten A, Van der Linden T, Duijm K, Van de Wouw M, Hermsen M, (1988) Instaptoets anderstalige volwassenen. Arnhem: CITO. 
Citation: Emmerik JV, Klatter J, Hout RV, de Craats IV, Schepens J (2014) Acquiring Nominal Gender by Deaf Learners and Hearing Adult Second Language Learners of Dutch. Commun Disord Deaf Stud Hearing Aids 2: 111. doi:10.4172/2375-4427.1000111

Page 9 of 9

25. Knoors H (2001) Taalontwikkelingsstoornissen ten gevolge van doofheid. Handboek Stem-spraak-taalpathologie 16: 1-34.

26. Niparko JK, Tobey EA, Thal DJ, Eisenberg LS, Wang NY, et al. (2010) Spoken language development in children following cochlear implantation. JAMA 303: 1498-1506.

27. Wiefferink K (2012) Cochlear implants in children. PhD Thesis, Leiden University.

28. Berman R, Slobin, D, Aksu-Koç A (1994) Relating events in narrative. Hillsdale, NJ: Lawrence Erlbaum Associates.

29. Botting $\mathrm{N}$ (2002) Narrative as a tool for the assessment of linguistic and pragmatic impairments. Child language teaching and therapy 18: 1-21.

30. Orgassa A (2009) Specific Language Impairment in a Bilingual Context The Acquisition of Dutch Inflection by Turkish-Dutch Learners. PhD Thesis, Utrecht University.
31. van der Lely HK (1997) Narrative discourse in Grammatical specific language impaired children: a modular language deficit? J Child Lang 24: 221-256.

32. Holmquist K, Johansson W, Stromquist S, Wengelin A (2002) Analysing reading and writing online. In: Stromquist $S$ and Uneson $M$ (eds) The diversity of languages and language learning. Lund: Lund University, pp. 103-123.

33. Verhoeven L and Vermeer A (2002) Taaltoets Alle Kinderen (TAK). Arnhem: CITO.

34. Kolen E (2009) De tweetalige ontwikkeling van dove kinderen in de Nederlandse gebarentaal en het Nederlands. PhD Thesis, Radboud University Nijmegen. 